\title{
Museu é lugar de criança sim senhor! a consonância entre a educação patrimonial e o ensino de história a partir de uma experiência do programa residência pedagógica da Unisc, em Santa Cruz do Sul/RS ${ }^{1}$
}

\author{
Yes sir, museum is a child's place! the consonance between patrimonial education and the teaching \\ of history based on an experience of the Pedagogical Residency Program of the Unisc, in Santa Cruz \\ do Sul/RS
}

\section{Eduardo Alexandre Louzado}

Gabriela Schwengber

\author{
Cícero Augusto Richter Schneider
}

Universidade de Santa Cruz do Sul - Unisc - Santa Cruz do Sul - Rio Grande do Sul - Brasil

\begin{abstract}
Resumo: Este trabalho discorre considerações acerca das relações entre a educação patrimonial e o ensino de história - dentro de uma perspectiva transversal, a partir de uma ação educativa com alunos e alunas da educação básica no Museu do Colégio Mauá, situado em Santa Cruz do Sul. Amostra desta pesquisa, uma turma de sexto ano do ensino fundamental da Escola Estadual de Educação Básica Estado de Goiás composta por 25 alunos e alunas apresentou, previamente, suas expectativas quanto à visitação do espaço museal. Realizada a visita ao museu, estes alunos e alunas apresentaram suas considerações acerca da experiência pedagógica vivenciada. A análise das prévias concepções e dos relatos posteriores à visitação são objeto das discussões deste trabalho. Tal atividade propiciou a materialização dos conceitos teóricos trabalhados previamente em sala de aula e reflexões acerca de aspectos históricos constitutivos da região a partir das seleções das peças expostas.
\end{abstract}

Palavras-chave: Ensino de História. Educação Patrimonial. Residência Pedagógica.

\begin{abstract}
This paper discusses considerations about the relationship between patrimonial education and the teaching of history - within a transverse perspective, from an educational activity with students of the basic education at the Museu do Colégio Mauá, located in Santa Cruz do Sul. As a sample of this research, a sixth grade elementary school series from the Escola Estadual de Educação Básica Estado de Goiás composed of 25 students, previously presented their expectations regarding the visitation of the museum space. After visiting the museum, these students presented their considerations about the pedagogical experience. The analysis of the previous conceptions and the reports after the visitation are the object of the discussions of this paper. Such activity provided the materialization of theoretical concepts previously worked in the classroom and reflections about the historical constitutive aspects of the region from the selection of the exhibited pieces.
\end{abstract}

Keywords: History Teaching. Patrimonial Education. Pedagogical Residence.

\footnotetext{
${ }^{1}$ Pesquisa financiada pela CAPES - Coordenação de Aperfeiçoamento de Pessoal de Nível Superior, através do Programa de Residência Pedagógica da Universidade de Santa Cruz do Sul.
} 


\section{Introdução}

A educação formal, enquanto espaço de construção de conhecimentos sistematizados é um campo que, por si só, demanda um constante (re)pensar não apenas dos aspectos formais do processo: planejamento, metodologia e avaliação mas principalmente do que é ensinado, para que e porquê ensinamos?

Em consonância, a formação de novos professores e professoras no biênio 2018-2019, na Universidade de Santa Cruz do Sul, conta com o programa Residência Pedagógica que propiciou a mais de 50 licenciandos e licenciandas a possibilidade de imersão no ambiente escolar da educação básica para, entre outras atividades, exercerem 100 horas de regência, na disciplina de formação acadêmica em andamento. Muito além do contato prévio com a rotina de uma sala de aula, este programa objetiva que os futuros docentes experimentem - e se experimentem, no processo de ensino aprendizagem construindo propostas, aplicando-as e, principalmente, avaliando os resultados obtidos a partir desta experiência.

Neste viés, a Educação Patrimonial e o ensino de História, focos desta pesquisa, apresentam-se como ferramentas de extrema importância dentro do processo formativo, propiciando uma leitura, (re)leitura e significância dos aspectos históricos constitutivos da sociedade, e em especial, da sociedade local.

Esta pesquisa foi realizada com uma turma de 25 alunos e alunas do sexto ano de ensino fundamental da Escola Estadual de Educação Básica Estado de Goiás - em Santa Cruz do Sul/RS, a partir de prática docente realizada por dois acadêmicos do curso de Licenciatura em História da Universidade de Santa Cruz do Sul, participantes do programa Residência Pedagógica desta instituição.

Base desta discussão apresentada, a visitação ao Museu do Colégio Mauá, objetivou aproximar os alunos e alunas da Escola Goiás de fontes históricas salvaguardadas neste espaço educativo, visando não somente a materialização dos conceitos teóricos trabalhados em sala de aula, mas proporcionar a estes alunos e alunas do sexto ano do ensino fundamental a possibilidade de (re)pensarem os aspectos históricos constitutivos da sociedade santa-cruzense e regional, a partir da representação existente nas peças e coleções ali expostas, almejando atender um dos objetivos gerais do ensino fundamental, segundo os parâmetros curriculares nacionais:

conhecer e valorizar a pluralidade do
patrimônio sociocultural brasileiro, bem
como aspectos socioculturais de outros
povos e nações, posicionando-se contra
qualquer discriminação baseada em
diferenças culturais, de classe social, de
crenças, de sexo, de etnia ou outras
características individuais e sociais
(BRASIL, 1998, p. 5)

Além da introdução e das considerações finais, este artigo apresenta quatro seções. A primeira apresenta os aspectos históricos constitutivos do município de Santa Cruz do Sul, apresentando a diversidade de influências étnicas que constituíram e constituem esta sociedade. $\mathrm{Na}$ sequência, apresenta o Museu do Colégio Mauá, seus objetivos e fins, bem como discute aspectos referentes as representações reforçadas através de suas peças e coleções expostas. A terceira seção dedica-se a apresentar o programa Residência Pedagógica e a Educação Patrimonial, seus vieses e contribuições para o ensino de História. Por fim, mas não menos importante, são apresentadas as reflexões dos alunos e alunas do sexto ano do ensino fundamental que participaram da atividade proposta.

\section{A "origem" de Santa Cruz do Sul}


Ao pensarmos a história de Santa Cruz do Sul, localizada na região do vale do Rio Pardo no estado do Rio Grande do Sul, é imprescindível que, logo de partida, haja a compreensão que a

[...] ocupação do território regional não inicia [...] apenas no século XVII com a instalação das reduções jesuíticas espanholas, ou com a penetração dos lusobrasileiros através das bandeiras de apresamento de índios e de gado, ou, no século XVIII, quando das incursões militares de portugueses e de espanhóis na disputa pela fixação da fronteira e pela dominação do território a ser colonizado, mas sim, bem antes, em tempos préhistóricos (SILVEIRA, 2008, p. 104 e 105).

Sendo assim, a história do então município, igualmente não se inicia com a fundação da Colônia de Santa Cruz por imigrantes alemães em 1849 processo e período tão ressaltados nas narrativas históricas do mesmo. Deve-se considerar que já havia a presença de diferentes povos indígenas por todo o estado sul rio-grandense (KLAMT, 2001, p.54), tais como os povos Umbu, a Humaitá, e Guarani (SILVEIRA, 2008, p. 105). Além disso, outras "fontes e pesquisas demonstram que desde meados do século XIX, quando chegados os primeiros imigrantes, já se faziam presentes na região: afro-descendentes; índios; caboclos e lusobrasileiros" (SKOLAUDE, 2010, p. 17). Segundo Vogt, os negros escravizados presentes na região

chegavam ao Rio Grande do Sul por intermédio dos comerciantes lusitanos e de seus correspondentes e trabalhavam tanto no meio rural, nos serviços domésticos ou das fazendas, quanto realizavam [...] ofícios diversos como carpinteiro, pedreiro, ferreiro, sapateiro e outros (VOGT, 2001, p.94).

Desta forma, quando se iniciou a criação da Colônia de Santa Cruz pela Câmara do município de Rio Pardo - que decidiu "abrir comunicação entre esta cidade e os campos de Cima da Serra por meio de uma estrada ou picada" (MENEZES, 2005, p. 26), a região não se encontrava completamente desabitada. No entanto, foi a partir da iniciativa riopardense que se passou a estabelecer esforços para a colonização da região, ocorrida mediante "concessões de algumas sesmarias de campos e matas a João de Faria Rosa e outros" (MENEZES, 2005 , p. 26), através da criação de uma lei provincial, em 1847, que estabelecia a necessidade da abertura de uma picada na região $e$, principalmente, pelas medidas tomadas pelo Governo Provincial em 1851, para "[...] promover a imigração europeia e melhorar o serviço de colonização" (MENEZES, 2005, p. 31).

Entre tais deliberações provinciais, organizadas em quinze artigos, constava a doação de terras de cem mil braças quadradas na colônia, gratificações de "três patacões por cada indivíduo de 7 a 35 anos" (MENEZES, 2005, p. 32), uma quantia de um conto e quinhentos réis por sujeito, além de conceder ferramentas e sementes para o cultivo. Desta forma, no mesmo ano "a Colônia já contava 93 lotes ocupados com cerca de 400 habitantes" (MENEZES, 2005, p. 34).

À vista disso, apesar de frequentemente encontrarmos narrativas históricas referente a cidade de Santa Cruz do Sul que abordam de forma exclusiva o processo de "chegada dos 12 primeiros imigrantes em dezembro de 1849" (SKOLAUDE, 2010 , p. 6) e enfatizam o desenvolvimento do município a partir dos elementos culturais e trabalho da etnia teuto, é imprescindível considerarmos que a localidade já era habitada por outras etnias, que, da mesma forma, são imprescindíveis para a constituição da cultura e município como tal, e assim, não devem ser invisibilizadas pela historiografia regional.

\section{O colégio mauá e seu museu}


Inicialmente, o Colégio Mauá possuía o nome de Deutsche Schule ${ }^{2}$, tendo sido fundado em 1949 por Hermann Jacob Bergfriede e possuía enquanto objetivo "[...] proporcionar uma educação de qualidade aos filhos dos imigrantes na Vila de Santa Cruz" (AGNES, 2018, p. 23). A partir daí, a instituição privada mudou diversas vezes sua nomenclatura devido a troca das mantenedoras ao decorrer dos anos, tendo estabelecido o nome de Colégio Mauá apenas em 1949 e mudado a escola para seu atual endereço, Rua Cristóvão Colombo, n 366 no município de Santa Cruz do Sul - RS, em 1981.

O Museu do Colégio Mauá, localizado na Rua Marechal Floriano, $n^{\circ} 274$, região central da cidade, teve seu projeto idealizado e construído pelo professor Hardy Martin e passou a ser aberto para visitações em 1966 - através de um convênio entre a mantenedora do Colégio Mauá, a Sociedade Escolar Santa Cruz e a Prefeitura Municipal (AGNES, 2018, p. 8). Alguns anos mais tarde, em 1981, também foi fundado o Arquivo Histórico do Colégio Mauá (AHCM) para reunir e organizar todo o acervo documental proveniente de doações.

A autora Lourdes Agnes, em O papel da coluna "Pesquisa" do Jornal Gazeta do Sul na formação do acervo do Museu do Colégio Mauá no período 1987-1996, enfatiza a importância da participação da comunidade santa-cruzense no processo de construção do acervo do museu figuras 01 , através de doações

[...] de diferentes tipologias, inicialmente, em grande número de peças arqueológicas oriundas de expedições exploratórias realizadas pelo interior do município onde agricultores eram informados sobre a importância das peças encontradas em suas lavouras. (AGNES, 2018, p. 28)

Figura 01: Parte da coleção arqueológica exposta no museu

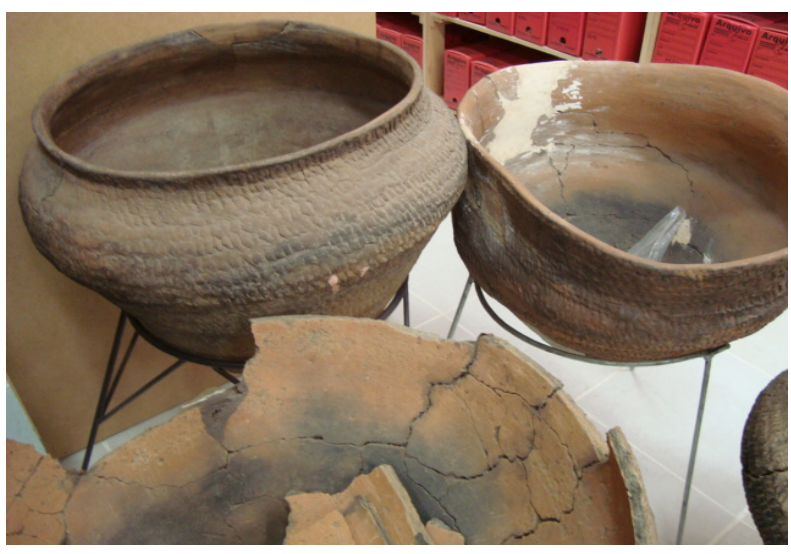

Fonte: Museu do Colégio Mauá (2018)

Agnes pontua que essa heterogeneidade nos teores das doações, conforme figura 02 , acontece em "grande parte dos museus de cidades no interior" que "recebem doações sem critérios, pela ausência de uma política de gestão de acervos implantada" (AGNES, 2018, p. 16).

Figura 02: Vista parcial da primeira sala de exposição do museu

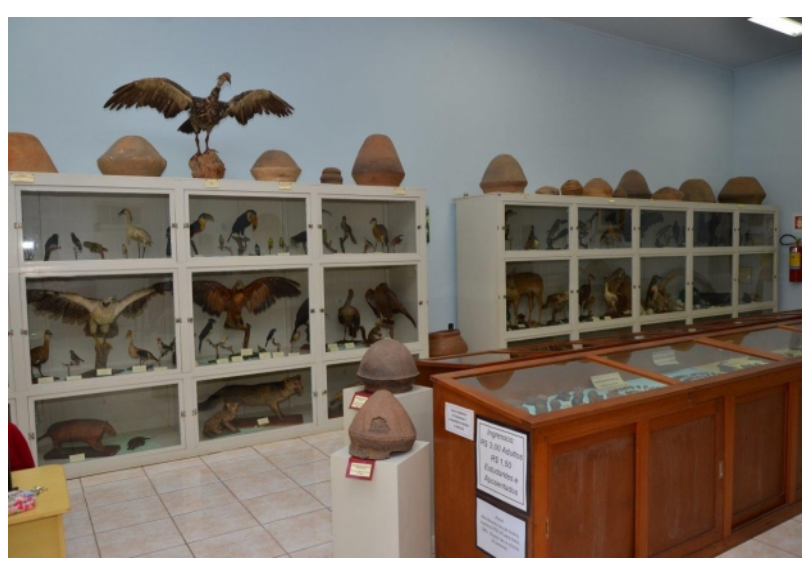

Fonte: Museu do Colégio Mauá (2018)

Esta autora também salienta a relevância da coluna Pesquisa presente em um dos jornais locais, Gazeta do Sul, escrita por Hardy Martin a partir de 1969. Nesta coluna o professor destacava as pesquisas arqueológicas do museu e abordava outros "[...] temas variados relacionados com a História da região, Etnologia, Geologia e ainda assuntos específicos relacionados ao museu como

\footnotetext{
${ }^{2}$ N.T.: Escola alemã.
} 
seus dados estatísticos sobre visitação, alteração de horários, manutenção, etc." (AGNES, 2018, p. 34).

A escrita de tal coluna foi de suma importância para divulgação do trabalho realizado pelo Museu do Colégio Mauá e "[...] foi uma das estratégias utilizadas pelo professor Hardy Martin para tornar público o acervo que estava sendo recebido no museu [...]" (AGNES, 2018, p. 61).

Através dessa interação, Agnes propõem figuras 03 e 04, que o "museu é o espaço que representa esta cidade, sua história, desenvolvimento, costumes, tradições e outros aspectos desde a criação da colônia de Santa Cruz até os dias atuais" (AGNES, 2018, p. 18).

Figura 03: Conjunto de porcelanas recebidas por doação da comunidade

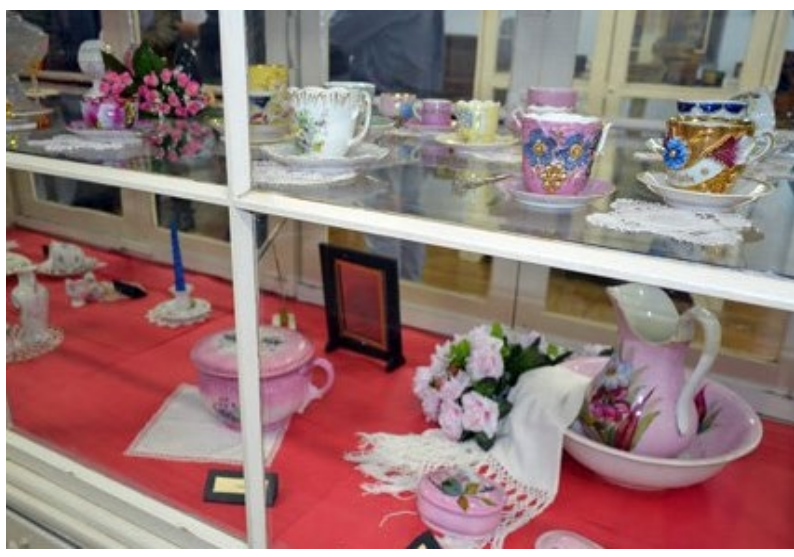

Fonte: Museu do Colégio Mauá (2018)
Figura 04: Caixa de música de origem suíça

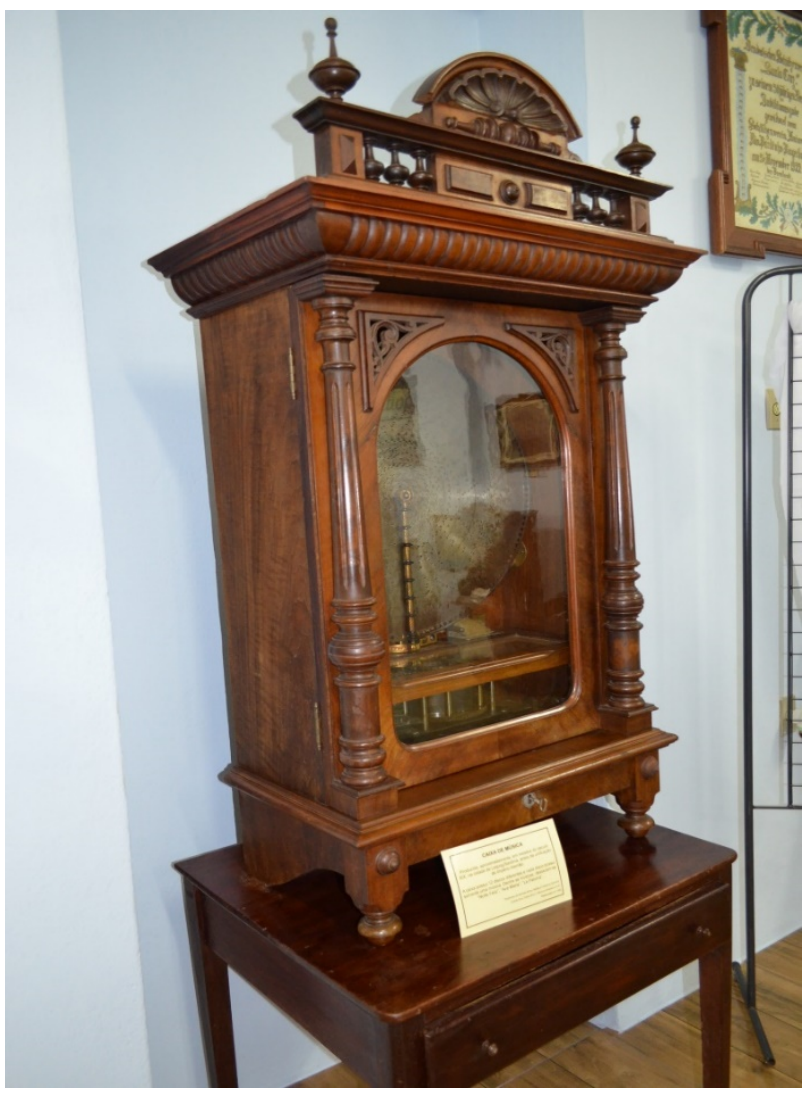

Fonte: Museu do Colégio Mauá (2018)

Em 1974, com a fundação do Centro de Estudos e Pesquisas Arqueológicas (CEPA) da Universidade de Santa Cruz do Sul (UNISC), a instituição de ensino superior passou a encabeçar as pesquisas na área da arqueologia e a receber as doações desses materiais. Posteriormente, o Arquivo Histórico do Colégio Mauá (AHCM) foi direcionado ao Centro de Documentação (CEDOC) da mesma universidade.

Atualmente, o Museu do Colégio Mauá ainda permanece enquanto uma referência sobre aspectos da história regional, bem como continua possibilitando visitas da comunidade em geral e, principalmente das escolas, para conhecer seu acervo que é composto por mais de 140 mil peças.

\section{$O$ (re)construir-se docente}

A Residência Pedagógica, enquanto programa de aperfeiçoamento da formação das licenciaturas, serve como uma experimentação 
teórico e prática dos acadêmicos, das mais diversas áreas do conhecimento, para a atuação como futuros professores. Segundo o site eletrônico da Coordenação de Aperfeiçoamento de Pessoal de Nível Superior (CAPES), o programa

é uma das ações que integram a Política Nacional de Formação de Professores e tem por objetivo induzir o aperfeiçoamento da formação prática nos cursos de licenciatura, promovendo a imersão do licenciando na escola de educação básica, a partir da segunda metade de seu curso (CAPES, 2018).

Este programa proporciona o contato com a realidade escolar - em seus múltiplos aspectos: planejamento e aplicação de aulas, participação em formações e atividades relacionadas à instituição em que atuarão enquanto bolsistas residentes, sob a devida tutela de professores orientadores na universidade e professor preceptor na escola de educação básica.

Segundo a Portaria $\mathrm{n}^{\circ} 38$, de 28 de fevereiro de 2018

Art. $2^{\circ}$ São objetivos do Programa de Residência Pedagógica:

I. Aperfeiçoar a formação dos discentes dos cursos de licenciatura, por meio do desenvolvimento de projetos que fortaleçam o campo da prática e que conduzam o licenciando a exercitar de forma ativa a relação entre teoria e prática profissional docente, utilizando coleta de dados e diagnóstico sobre o ensino e a aprendizagem escolar, entre outras didáticas e metodologias. (CAPES, 2018, p.1)

Portanto, fica claro nos objetivos da Residência Pedagógica, que este programa visa ser não apenas um "treinamento" para o exercício docente em sala de aula, mas também, propiciar a prática de outras didáticas e metodologias, oportunizando desta forma, a experimentação da criação de projetos e/ou atividades que tenham por objetivo otimizar a construção do conhecimento através do estabelecimento de relações com os conteúdos aprendidos em sala de aula por parte dos alunos, e, na esfera dos bolsistas residentes, a idealização, criação e aplicação de diferentes propostas de trabalho e atividades que possibilitem um aprendizado significativo na prática docente.

Em Santa Cruz do Sul/RS, os acadêmicos do curso de licenciatura em História da Universidade de Santa Cruz do Sul - UNISC, foi definida como instituição de atuação a Escola Estadual de Educação Básica Estado de Goiás.

Em conjunto com o professor preceptor na Escola Goiás, foi criada a proposta de atividade de visitação ao Museu do Colégio Mauá, a partir dos pressupostos da Educação Patrimonial.

Tal projeto foi pensado com o objetivo de proporcionar aos alunos participantes 0 estabelecimento de relações entre o conteúdo apresentado em aula e os objetos do acervo do museu - reforçando a construção do conhecimento e o desenvolvimento de conceitos históricos tais como: o de patrimônio, fontes históricas e a própria noção de tempo; além de possibilitar uma visualização de peças e instrumentos tratados em aula apenas no aspecto teórico.

Para além, a atividade visualizava possibilitar também uma melhor compreensão do próprio conceito de História - reafirmando-o como um estudo do homem no tempo e que, sendo assim, não é uma coisa estanque, mas, sim, em constante movimento (BLOCH, 2001), proporcionando, portanto, "que o aluno abra enormes horizontes que podem acolher, inicialmente, sua curiosidade, depois, sua análise e, finalmente, sua identificação com essa 'gente como a gente', que construiu o processo histórico do qual ele mesmo faz parte" (PINSKY; PINSKY, 2004, p. 35).

Convém resgatar que a educação patrimonial passou a ser discutida como tal (e sob esse nome) a partir da década de 1980 no Brasil (FRATINI, 2009), remontando, contudo, ao surgimento do Serviço do Patrimônio Histórico e Artístico Nacional (SPHAN), em 1937, em suas buscas pela resguarda do patrimônio. 
Em uma célere definição, de acordo com Evelina Grunberg (2007, p. 5), "chamamos de Educação Patrimonial o processo permanente e sistemático de trabalho educativo, que tem como ponto de partida e centro o Patrimônio Cultural com todas as suas manifestações". Com isso, ressaltase, portanto, o que é tomado por patrimônio cultural segundo o artigo 216 da Constituição Federal do Brasil,

Patrimônio cultural é formado por bens de natureza material e imaterial, tomadas individualmente ou em conjunto, portadores de referência à identidade, à ação, à memória dos diferentes grupos formadores da sociedade brasileira, nos quais se incluem: I - as formas de expressão; II - os modos de criar, fazer e viver; III - as criações científicas e tecnológicas; IV - as obras, objetos, documentos, edificações e demais espaços destinados às manifestações artístico-culturais; V - os conjuntos urbanos e sítios de valor histórico, paisagístico, arqueológico, paleontológico, ecológico e científico. (BRASIL, 1988)

O patrimônio cultural, em seus mais diversos tipos, guardam em si a memória ou a manifestação de uma identidade ou de um discurso que faz referência aos diferentes povos e grupos que compõem a construção da sociedade, cultura e história brasileira. Esses bens podem ser de caráter material ou imaterial, abordando, portanto, tanto as edificações, instrumentos e complexos arquitetônicos do Brasil como, também, suas mentalidades, formas de expressão, de ver e de fazer.

Assim, a Educação Patrimonial visa um processo formativo que sensibilize sobre a importância dos bens tombados e em acervos, considerando sua carga histórica e simbólica atuante na construção da realidade social em que vivem, como postulam Horta, Grunberg e Monteiro (1999, p. 4),

a Educação Patrimonial é um instrumento de "alfabetização cultural" que possibilita ao indivíduo fazer a leitura do mundo que o rodeia, levando-o à compreensão do universo sociocultural e da trajetória histórico-temporal em que está inserido. Este processo leva ao reforço da autoestima dos indivíduos e comunidades e à valorização da cultura brasileira, compreendida como múltipla e plural [grifos das autoras].

Corroborando a noção apresentada pelas autoras, sobre a Educação Patrimonial, afirma Saballa que (2007, p. 23-24)

aos indivíduos é permitida a realização da leitura do mundo no qual se inserem, percebendo-se como parte integrante de um grupo. A noção de pertença leva à mobilização, concebendo o sentido da participação e integração pelo elaborado e projetado na coletividade, pelo valor partilhado, restabelecendo assim, o passado através de objetos pertencente ao seu universo, percebendo-se sujeitos da História.

Entende-se, portanto, que a Educação Patrimonial é de grande importância na construção do conhecimento dos alunos, visto que auxilia na elaboração da consciência das construções simbólicas, culturais e identitárias que compõem o mundo em que eles vivem e que os rodeia. Além disso, permite, também, situar o discente como um sujeito ativo na História, explicitando como o processo histórico se deu e resultou na realidade em que esse aluno se encontra. Por fim, permite, também, de acordo com as possibilidades, estabelecer uma conexão visual e material entre os estudantes e os temas vistos por eles em aula.

Deve-se notar que

educação aqui é pensada como processo. Dessa forma, educação significa reflexão constante e ação transformadora dos sujeitos no mundo e não uma educação somente reprodutora de informações, como via de mão única e que identifique os educandos como consumidores de informações (...). (FLORÊNCIO, 2015, p. 26)

Faz-se oportuno ressaltar que o trabalho com o patrimônio visa a construção do pensamento crítico por parte do aluno, uma vez que o discente, em contato com o patrimônio cultural, tornar-se apto 
a realizar a própria leitura sobre o espaço em que está e sua construção simbólica, histórica e cultural.

\section{Aprendendo história fora da escola}

A visitação ao Museu do Colégio Mauá foi proposta a um grupo de 25 alunos do $6^{\circ}$ ano do ensino fundamental da Escola Estadual de Educação Básica Estado de Goiás, de Santa Cruz do Sul/RS.

Este grupo de alunos é formado por 13 meninas e 12 meninos, possuindo idade entre 11 e 12 anos. Do total de alunos desta turma, apenas 20\% dos alunos (03 meninos e 02 meninas) já haviam visita um museu - independente da tipologia, entretanto nenhum destes havia visitado o Museu do Colégio Mauá.

As expectativas dos alunos e alunas, quanto a função de um museu, pesquisada através de questionário anterior à visitação apontou em sua quase totalidade, a concepção que

\begin{abstract}
"um museu para mim é um lugar onde nós estudamos e vamos para vermos objetos do passado e artes de pessoas bem famosas" (ANM, menina, 11 anos);

"é uma casa para coisas antigas que marcaram ou mudaram o mundo" (CHK, menina, 11 anos);

"o museu é um lugar onde as coisas antigas que são interessantes ficam" (MR, menino, 12 anos).
\end{abstract}

Tais expectativas, foram confirmadas ao entrarem em contato direto com o acervo de objetos produzidos e deixados por gente como eles, participantes do processo histórico de construção do cenário local - seja do município, do estado ou do país, permitindo que os estudantes edifiquem sua própria visão sobre como seus ancestrais viviam, o que faziam, como era sua cultura e sua sociedade, seus costumes e crenças. Esses assuntos são, muitas vezes, vistos em aula de maneira muito abstrata e distante.

O grupo de alunos e alunas foi questionado anteriormente a visitação, se visualizavam a possibilidade de a visita ao museu ajudar a compreender as aulas de história. A totalidade de alunos respondeu que sim, destacando-se as justificativas

\begin{abstract}
"pois lá existe muitas coisas/fontes que podem nos ajudar a compreender o 'nosso' passado" (KLM, menina, 12 anos);

"porque a história gosta de estudar o passado então, como lá tem coisas do passado, acho que sim" (JJFS, menina, 12 anos);

"se for um museu de fósseis por exemplo, ajuda muito" (HRA, menino, 12 anos);

"no museu tem coisas da história do nosso mundo e também algumas coisas que estudamos em aula" (JV, menina, 11 anos); "porque lá os professores vão mostrar tudo e o que é cada coisa" (MR, menino, 12 anos);

"porque podemos ver mais de perto e entender melhor algumas coisas"(FDF, menina, 11 anos).
\end{abstract}

A Educação Patrimonial - em especial a educação museal, nesse aspecto, aproximou os alunos e alunas dos indivíduos/artefatos de quem tanto ouvem falar por meio de seu professor de História.

Contextualizando, por sua vez, a esfera da docência, no contexto da Residência Pedagógica, a visitação ao Museu do Colégio Mauá figura-se como uma atividade prática de Educação Patrimonial muito construtiva para a formação dos bolsistas residentes, futuros professores de História.

Primeiramente, deve-se citar a experiência de, estando na posição de regentes de turma (na atividade, devidamente acompanhados pelo preceptor), visualizar os efeitos e possibilidades surgidas com uma atividade fora de sala de aula, e em contato com fontes históricas reais, físicas, e não simplesmente projetadas através de um Datashow.

Além disso, em segundo ponto, deve-se ressaltar, no âmbito da formação acadêmica dos mesmos, o planejamento das atividades, fazendo uso da construção do conhecimento realizada no acervo, e as relações estabelecidas com os conteúdos trabalhados em aula, visto que "cabe ao 
historiador escolher e lançar mão das evidências materiais e/ou imateriais de forma própria e original para construir o seu texto sobre memória, sobre patrimônio e/ou sobre a história" (SILVEIRA; RAMOS, 2016, p. 15). Por fim, um terceiro ponto deve ser ressaltado, em que, de acordo com Teixeira (2008, p. 206), afirma-se que

\begin{abstract}
A Educação Patrimonial no ensino de História viabiliza a formação de indivíduos capazes de conhecer a sua própria história cultural. Ao trabalharmos questões referentes ao patrimônio no ambiente escolar, estamos oferecendo subsídios para a construção do conhecimento e da valorização e preservação desses bens culturais, sejam eles materiais, imateriais, naturais ou construídos. Ações educativas nesse sentido são importantes na medida em que os indivíduos precisam, para se reconhecerem e se diferenciarem de outros, de um "espelho" onde seja possível ver a própria vida, a própria cultura, a própria história e as próprias práticas e, com isso, construir a sua memória afetiva e sua identidade cultural.
\end{abstract}

Deve-se ressaltar que o museu, por si só, é um espaço discursivo, simbólico e de memória. Esse local (o museu) foi organizado por uma pessoa, grupo ou instituição, tendo em sua elaboração uma lente, uma visão de mundo que define a forma como o acervo é disposto. Um museu é um espaço de afirmação de uma identidade, de caráter nacional ou local, que garante um certo reconhecimento cultural e de civilidade, reforçando essa memória social comum à nação ou a um grupo específico (ALVES; REIS, 2012.).

Portanto, independente do simbolismo e/ou origem do valor, a organização e a preservação de coleções busca, ao longo dos tempos, a perpetuação, não somente do objeto material, mas também, o suporte de memórias do colecionador, de um grupo ou de uma sociedade (LOUZADO; COSTA, 2015, p. 172.).

Assim, um dos aspectos convenientes da atividade é a possível problematização sobre o discurso que o local dispõe, e não apenas sobre as peças de seu acervo. Deve-se pontuar aos alunos que o museu, por si só, possui um significado e uma produção histórica.
Aos alunos e alunas, foi proposto em sala de aula, após a visita ao museu, que apresentassem/destacassem o que aprenderam com esta atividade

\begin{abstract}
"tem muitas coisas de alemão, que é o que os antepassados da gente eram, mas tem objetos de índios e outras pessoas, então todo mundo é importante" (VFC, menina, 12 anos);

"os índios enterravam as pessoas dentro de grandes vasos de barro, bem diferente da gente, pelo menos eu acho. Não sei se é certo ou errado, a gente tem que aprender a respeitar o que é diferente" (AHK, menina, 12 anos);

"museu é muito legal, é melhor ver os fósseis de perto, mesmo sendo parecidos com o livro, olhar eles lá é bem mais legal" (HRA, menino, 12 anos);

"as pessoas sempre foram muito inteligentes, até nos tempos atrás eles construíam armas para caçar com o que tinha na natureza" (ID, menina, 11 anos); "os índios são muito inteligentes, mesmo não indo para a escola, eles aprendiam e ensinavam tudo para as crianças" (MR, menino, 12 anos);

"museu é muito legal, eu achava que seria tipo assim meio feio, por só ter coisas de antigamente, mas é ótimo para a gente aprender mais" (FDF, menina, 11 anos).
\end{abstract}

Quanto ao acervo em si, há uma grande possibilidade de construção de conceitos históricos e de relações por parte dos alunos. Tome-se, por exemplo, o link que pode ser produzido entre o conteúdo do período da hominização (período da chamada "Pré-História"), trabalhado nas aulas ministradas pelos bolsistas residentes e peças tais como pontas de flechas, boleadeiras, pedaços de cerâmica e instrumentos diversos do recorte temporal correspondente, presentes na coleção do Museu do Colégio Mauá.

Pode-se dizer, portanto, que a visita ao museu e a análise de seu acervo e de seu contexto possibilita uma melhor construção do saber por parte dos discentes. Esse conhecimento por eles adquirido vai além do que é possibilitado apenas pela experiência em sala de aula como apresentam Desvallées e Mairesse (2010, p. 32-33) 
La educación, en un contexto específicamente museal, está unida a la movilización de los saberes surgidos del museo, con miras al progreso y al florecimiento de los individuos. A través de la integración de esos conocimientos se logra el desarrollo de nuevas sensibilidade y nuevas experiencias. ${ }^{3}$

\section{Considerações finais}

As múltiplas vivências, dentro de um processo formativo, auxiliam na significância dos conhecimentos, na materialização de conceitos e principalmente na reflexão dos processos constitutivos destes conhecimentos.

A Educação Patrimonial, ao ser entendida como um processo sistemático e contínuo, que visa a valorização do indivíduo e do coletivo, a partir de seu Patrimônio Cultura, é uma - entre tantas oportunidades, de (re)significação de conhecimentos para a emancipação social dos alunos e alunas, quer seja na educação formal ou não formal.

Ao tomar contato direto com o patrimônio material/fontes históricas - caso específico deste estudo, a experiência vivencial no Museu do Colégio Mauá propiciou aos alunos e alunas do $6^{\circ}$ ano do ensino fundamental da Escola Estadual de Educação Básica Estado de Goiás a compreensão de diversos conceitos históricos, trabalhados na disciplina de História, em sala de aula.

Não limitando-se aos conteúdos pertinentes ao ensino formal de História, do $6^{\circ}$ ano da educação básica, as reflexões construídas pelos alunos e alunas, após a visitação, avançaram em temas transversais como Cidadania, Meio Ambiente e Saúde.

Tais reflexões reforçam não apenas o caráter interdisciplinar de ações educativas em espaço museal, mas o fomento a uma intrínseca tessitura de conhecimentos fundamentais ao

${ }^{3} \mathrm{~N}$. T. "A educação, em um contexto especificamente museal, está unida à mobilização dos saberes surgidos do museu, com vistas ao progresso e ao florescimento dos indivíduos. Através conhecimento e (re)conhecimento plural da constituição histórico-social local e nacional.

Entretanto, a transversalidade de temas, ou temas transversais, por estarem entendidos - e é claro este entendimento: como permeadores de diversas áreas do conhecimento ou componentes curriculares encontra nesta situação, uma das barreiras pedagógicas para sua realização, uma vez que para uma significativa parcela de professores e professoras, o tema transversal é componente de todas as disciplinas - a entender: todas, menos o que ele/ela leciona. E este pensamento, em muito arraigado a um certo conformismo de uma formação clássica, disciplinar, promotora de conceitos acadêmicos pouco significativo e representativo para os alunos e alunas, em pouco contribui para o viés estruturante da Educação Patrimonial: a interdisciplinaridade (LOUZADO, COSTA, 2015, p.131).

Portanto, o projeto visitação ao Museu do Colégio Mauá, com alunos e alunas do sexto ano do Ensino Fundamental da Escola Goiás, possibilitou uma integração dos conhecimentos trazidos pelos alunos, aprendidos em sala de aula e presentes no acervo do museu (note-se a grande carga histórica, simbólica e de memória presente neste).

Com esta abordagem, oportunizou-se aos discentes que, a partir da vivência experimentada, consigam estabelecer relações entre o patrimônio cultural por eles analisado e o conteúdo visto nas aulas de História, e que a experiência no museu sirva como um mobilizador no desenvolvimento de conhecimentos e conceitos históricos, para além das noções de patrimônio, cultura e identidade.

\section{Referências}

AGNES, Lourdes Maria. O papel da coluna "Pesquisa" do Jornal Gazeta do Sul na formação do acervo do Museu do Colégio Mauá no período de 1987-1996. Trabalho

da integração desses conhecimentos se consegue o desenvolvimento de novas sensibilidades e novas experiências". 
de conclusão de curso da Universidade Federal do Rio Grande do Sul, Faculdade de Biblioteconomia e Comunicação, Curso em Museologia. Porto Alegre, 2018.

ALVES, Vânia Maria Siqueira; REIS, Maria Amélia Gomes de Souza. Museus escolares: concepções e evolução de uma identidade no Brasil. Comunicação oral. XIII Encontro Nacional de Pesquisa em Ciência da Informação - XIII ENANCIB, 2012. Rio de Janeiro, 2012. Disponível em: $<$ file:///C:/Users/User/Downloads/MUSEUS $\%$ 20ESCOLARES\%20(1).pdf>. Acesso em: 30 jun. 2019.

BLOCH, Marc Leopold Benjamin. Apologia da história, ou, $\mathrm{O}$ ofício de historiador. Traduzido por: André Telles. Rio de Janeiro: Zahar, 2001.

BRASIL. Constituição da República Federativa do Brasil de 1988. Brasília, DF: Presidência da República, 2019. Disponível em: $<$ http://www.planalto.gov.br/ccivil 03/consti tuicao/constituicao.htm>. Acesso em: 29 jun. 2019.

Parâmetros Curriculares Nacionais (PCNS). Introdução. Ensino Fundamental. Brasília: MEC/SEF, 1998.

CAPES. Portaria Gab. $N^{\circ} 38$, de 28 de Fevereiro de 2018. Institui o Programa de Residência Pedagógica. Disponível em: $<$ http://www.capes.gov.br/images/stories/d ownload/legislacao/28022018-

Portaria n 38-Institui RP.pdf>. Acesso em: 28 jun. 2019.

CAPES. Programa de Residência Pedagógica. Disponível em: $<$ http://www.capes.gov.br/pt/educacaobasica/programa-residencia-pedagogica>. Acesso em: 28 jun. 2019.

COLÉGIO MAUÁ. Museu do Colégio Mauá, espaço histórico-cultural. Disponível em: $<$ http://www.maua.g12.br/museus. Acesso em: 3 jun. 2019.

DESVALLÉES, André; MAIRESSE, François (orgs.). Conceptos claves de museología. Paris: Armand Colin, 2010. Disponível em: $<$ https://www.academia.edu/26792135/Con ceptos claves de museolog\%C3\%ADa>. Acesso em: 30 jun. 2019.

FLORÊNCIO, Sônia Regina Rampim. Educação Patrimonial: algumas diretrizes conceituais. In: PINHEIRO, Adson Rodrigo $S$ (org.). Cadernos do patrimônio cultural: educação patrimonial. Fortaleza: Secultfor: IPHAN,
2015.

Disponível

em:

$<$ http://portal.iphan.gov.br/uploads/publicac ao/EduPat Cadernos do patrimonio educ acao patrimonial voll(3).pdf>. Acesso em: 30 jun. 2019.

FRATINI, Renata. Educação patrimonial em arquivos. Artigo. Histórica, $\mathrm{n}^{\circ}$ 34, 2009 (Revista do Arquivo Público do Estado de São Paulo) - Arquivo Público do Estado de São Paulo, São Paulo, 2009. Disponível em: $<$ http://www.historica.arquivoestado.sp.gov. br/materias/anteriores/edica034/materia05/t exto05.pdf>. Acesso em: 30 jun. 2019.

GRUNBERG, Evelina. Manual de atividades prática de educação patrimonial. Brasília, DF: IPHAN, 2007. Disponível em: $<$ https://moodle.ufsc.br/pluginfile.php/5586 06/mod resource/content/0/GRUNBERG Evelina.pdf>. Acesso em: 30 jun. 2019.

HORTA, Maria de Lourdes Parreira; GRUNBERG, Evelina; MONTEIRO, Adriane Queiroz. Guia básico da educação patrimonial. Brasília, DF: IPHAN, 1999. Disponível em: $<$ http://portal.iphan.gov.br/uploads/temp/gui a educacao patrimonial.pdf.pdf>. Acesso em: 30 jun. 2019.

KLAMT, Sergio Celio. A ocupação pré-colonial no Vale do Rio Pardo, RS. In: VOGT, Olgário P.; SILVEIRA, Rogério L. da (Organizadores). Vale do Rio Pardo: (re)conhecendo a região. Santa Cruz do Sul: EDUNICS, 2001.

LOUZADO, Eduardo Alexandre; COSTA, Heloisa Helena Fernandes Gonçalves da. Seleção Cultural: (re)pensando o Museo Casa Isleña de San Andrés / Colômbia, a partir de suas peças, coleções e objetivos. Artigo. Políticas Culturais em Revista, 1(8), p. 171184, 2015. Disponível em: $<$ https://portalseer.ufba.br/index.php/pcultur ais/article/view/13744/9756>. Acesso em: 30 jun. 2019.

MENEZES, João Bittencourt de. Município de Santa Cruz do Sul. 2. ed./texto transcrito em ortografia atualizada por Arthur Rabuske. Santa Cruz do Sul: EDUNISC, 2005.

PINSKY, Jaime; PINSKY, Carla Bassanezi. Por uma história prazerosa e consequente. In: KARNAL, Leandro (org.). História na sala de aula: conceitos, práticas e propostas. 2. ed. São Paulo: Contexto, 2004.

SABALLA, Viviane Adriana. Educação Patrimonial: "Lugares de Memória. Artigo. Revista Mouseion, v. 1, junho/2007 (Revista do Museu e Arquivo Histórico La Salle) - 
Universidade La Salle (UNILASALLE), Canoas, 2007. Disponível em: $<$ https://biblioteca.unilasalle.edu.br/docs o nline/artigos/mouseion/2007 v1 n1/vasaba lla.pdf>. Acesso em: 30 jun. 2019.

SILVA, Mozart Linhares da. Educação e etnicidade na região de Santa Cruz do Sul - RS. Revista Eletrônica de Educação, v. 6, n. 2, 2012. Programa de Pós-Graduação em Educação, Universidade Federal de São Carlos, Brasil. Disponível em: <http://www.reveduc.ufscar.br/index.php/re veduc/article/view/285/205>. Acesso em: 28/06/2019.

SILVEIRA, Éder da Silva; RAMOS, Eloisa Helena Capovilla da Luz. A produção do conhecimento histórico sobre memória e patrimônio: algumas considerações sobre o uso das fontes e notas preliminares para o professor/historiador em formação. In: NASCIMENTO, José Antonio Moraes do (org.). Centros de documentação e arquivos: acervos, experiências e formação. São Leopoldo: Oikos, 2016.

SILVEIRA, Rogério Leandro Lima da. Ocupação e primeiros usos do território na região do Vale do Rio Pardo - RS: dos primeiros habitantes indígenas à apropriação militar dos campos de Rio Pardo. Redes. Revista Desenvolvimento Regional, Santa Cruz do Sul, v. 13, n. 2, 2008. Disponível em: < https://www.redalyc.org/pdf/5520/55205685 4004.pdf>. Acesso e: 11 jul. 2019.

SKOLAUDE, Mateus Silva. História, identidade e representação social: o caso da comunidade afro-descendente de Santa Cruz do Sul. $5^{\circ}$ encontro Escravidão e Liberdade no Brasil Meridional, 2010. Disponível em: <http://www.escravidaoeliberdade.com.br/s ite/images/Textos $5 /$ skolaude $\% 20$ mateus $\%$ 20silva.pdf>. Acesso em: 28/06/2019.

SPINDLER, Guilherme Würdig; RADÜNZ, Roberto; VOGT, Olgário Paulo. Escravos na povoação de Santa Cruz na segunda metade do século XIX. Revista Jovens Pesquisadores, Santa Cruz do Sul, v. 6, n. 2, nov. 2016. Disponível em: $<$ https://online.unisc.br/seer/index.php/jove nspesquisadores/article/view/7386>.

Acesso em: 29/06/2019.

TEIXEIRA, Cláudia Adriana Rocha. A educação patrimonial no ensino de história. Artigo. Biblos, v. 22, n. 1 (Revista do Instituto de Ciências Humanas e da Informação FURG) - Universidade Federal do Rio Grande, Rio Grande, 2008. Disponível em: <https://periodicos.furg.br/biblos/article/vie w/868/347>. Acesso em: 30 jun. 2019.

VOGT, Olgário P.; SILVEIRA, Rogério L. da (Organizadores). Vale do Rio Pardo: (re)conhecendo a região. Santa Cruz do Sul: EDUNICS, 2001. 